\title{
Exigência de lisina pela Tilápia do Nilo (Oreochromis niloticus), na fase de terminação
}

\author{
Lysine requirement of Nile Tilapia (Oreochromis niloticus), for grow-out phase
}

\author{
Wilson Massamitu Furuya ${ }^{1}$ Daniele Botaro² Patrícia Ribeiro Neves $^{2}$ Lilian Carolina Rosa Silva ${ }^{2}$ \\ Carmino Hayashi ${ }^{3}$
}

\section{RESUMO}

O presente estudo foi realizado para determinar a exigência de lisina pela tilápia do Nilo (Oreochromis niloticus). Setenta e dois peixes revertidos sexualmente e com peso vivo médio inicial de 117,9 \pm 0,67g foram alimentados por 50 dias com quatro rações (25\% proteína bruta e $3090 \mathrm{kcal}$ de energia digestível $\mathrm{kg}^{-1}$ ) contendo diferentes teores de inclusão de L-Lisina $\mathrm{HCl}: 0,1 ; 0,3 ; 0,5$ e 0,7\%, correspondente a rações com 1,13; 1,$27 ; 1,42$ e $1,57 \%$ de lisina, respectivamente. Os peixes foram distribuídos em 12 tanques com volume de 1000L cada, num delineamento inteiramente casualizado com quatro tratamentos, três repetições e seis peixes por unidade experimental. Não foram observadas diferenças na temperatura, pH, oxigênio dissolvido, condutividade elétrica e transparência da água nos diferentes tratamentos. Não foi observado efeito $(P>0,05)$ dos teores de inclusão de lisina sobre a taxa de sobrevivência, conversão alimentar, gordura visceral, índice hepato-somático e rendimento de carcaça. Foi observado efeito quadrático $(P<0,05)$, sobre o ganho de peso e taxa de eficiência protéica, estimando-se os valores de 1,42\% (5,7\% da proteína ou 4,8mg de lisina/kcal de energia digestível na ração) e 1,35\% (5,4\% da proteína) de lisina, respectivamente. Considerando-se desempenho, foi determinada exigência de 1,42\% de lisina $(5,7 \%$ da proteína ou 4,8 mg de lisina/kcal de energia digestível na ração) em rações para tilápia do Nilo na fase de terminação.

Palavras-chave: desempenho, exigência, lisina, Oreochromis niloticus, terminação.

\section{ABSTRACT}

The present study was carried out to determine the lysine requirement for Nile tilapia (Oreochromis niloticus). Seventy two reversed fish with average weight initial of $117.9 \pm$ $0.67 \mathrm{~g}$ were for by 50 days with four diets $(25 \%$ of crude protein and $3090 \mathrm{kcal} \mathrm{kg}^{-1}$ of digestible energy) containing different values of inclusion of L-Lysine $\mathrm{HCl}: 0.1 ; 0.3 ; 0.5$ and $0.7 \%$, corresponding to rations with $1.13 ; 1.27 ; 1.42$ and $1.57 \%$ of lysine, respectively. Fish were distributed in 12 tanks of 1000-L each, in a completely randomized design with four treatments, three replicates and six fish per experimental unit. No differences were observed in the temperature, $\mathrm{pH}$, dissolved oxygen and electric conductivity of the water in the different treatments. No effects $(P>0.05)$ of lysine inclusion were observed on survival rate, feed conversion, visceral fat, hepatosomatic index and carcass yield. There was no sign of quadratic effect $(P<0.05)$ on weight gain and protein efficiency ratio, estimating the requirements values of $1.42 \%$ (5.7\% of crude protein or $4.8 \mathrm{mg}$ of lysine $\mathrm{kcal}^{-1}$ of digestible energy in diet) and $1.35 \%$ of lysine (5.4\% of crude protein), respectively. Considering the performance, a requirement value of $1.42 \%$ of lysine $15.7 \%$ of protein or $4.8 \mathrm{mg}$ of lysine/kcal of digestible energy in diet) was obtained for Nile tilapia, in grow-out phase.

Key words: lysine, Oreochromis niloticus, performance, requirement, termination.

\section{INTRODUÇÃO}

A tilápia do Nilo (Oreochromis niloticus) é considerada uma das espécies mais promissoras para a piscicultura, pelo rápido crescimento em sistema intensivo, pela rusticidade e por possuir carne com boas características organolépticas e filé sem espinhos intramusculares em "Y" (HILDSORF, 1995). De hábito alimentar onívoro, consome ração logo após o início da alimentação exógena e utiliza eficientemente os carboidratos como fonte de energia (HANLEY, 1987; DEGANI \& REVACH, 1991).

A farinha de peixe é a fonte de proteína de origem animal mais utilizada em rações para peixes, pelo elevado conteúdo de proteína com adequado balanceamento de aminoácidos, constituindo-se ainda

${ }^{1}$ Professor, Departamento de Zootecnia, Universidade Estadual de Maringá (UEM), Av. Colombo, 5790, 87020-900, Maringá-PR. E-mail: wmfuruya@uem.br.

${ }^{2}$ Alunos do Curso de Graduação em Zootecnia, UEM. E-mail: danibot13@ hotmail.com.

${ }^{3}$ Professor, Dr, Departamento de Biologia, UEM. E-mail: chayashi@uem.br. 
como fonte de minerais, vitaminas e de energia digestível (FURUYA et al., 2001). Pelo seu elevado custo, têm-se avaliado fontes alternativas de proteína para reduzir o custo com a alimentação. Os ingredientes de origem vegetal têm sido utilizados em substituição à farinha de peixe, pelo menor custo e disponibilidade no mercado. Por apresentarem limitação em alguns aminoácidos, geralmente necessitam de suplementação, quando utilizados em rações para organismos aquáticos.

Para adequada suplementação de aminoácidos, faz-se necessário o conhecimento das suas exigências. Dentre os aminoácidos essenciais, a lisina está presente em elevada proporção no tecido muscular dos peixes, sendo exigido em grande quantidade na ração. A lisina sintética é utilizada menos eficientemente que a lisina ligada à proteína dos ingredientes. De acordo com YAMADA et al. (1981) e SCHUHMACHER et al. (1997), o menor desempenho obtido com peixes recebendo aminoácidos sintéticos pode ser atribuído a sua rápida absorção, com súbita elevação nos seus níveis plasmáticos, atingindo o pico anteriormente ao dos peixes alimentados com proteína intacta do alimento. Isto eleva o catabolismo e a excreção de compostos nitrogenados (CHEN et al., 1992; LIM, 1993).

No efluente de piscicultura, o nitrogênio é considerado a principal fonte de poluição, podendo resultar em elevada eutrofização (RICHIE \& BROWN, 1996), produzindo compostos tóxicos aos peixes (ENGLISH et al., 1993) e, no caso de predomínio de cianobactérias, pode prejudicar as características organolépticas da carcaça dos peixes por provocar "off flavor" (VAN DER PLOEG \& BOYD, 1991; VAN DER PLOEG \& TUCKER, 1994). As perdas metabólicas de nitrogênio podem ser minimizadas pela redução do intervalo de arraçoamento, que mantêm a concentração plasmática mais estável (TANTIKITTI \& MARCH, 1995) e reduz as perdas de aminoácidos sintéticos, que são altamente solúveis no meio aquático, em relação aos ligados à proteína (ZARATE \& LOVELL, 1997).

Os peixes carnívoros necessitam de rações com teores elevados de lisina, sendo que a suplementação desse aminoácido está estreitamente relacionada com o aumento no ganho de peso, melhora na conversão alimentar, aumento na retenção de nitrogênio e redução no conteúdo de lipídios na carcaça (BAI \& GATLIN, 1994; DAVIS et al., 1997; BERGE et al., 1998). Para "sea bass" (Dicentrarchus labrax) $(0,85 \mathrm{~g})$ alimentados com rações semi-purificadas, TIBALDI \& LANARI (1991), determinaram exigência de 2,22\% de lisina para melhor desempenho e retenção de proteína na carcaça.

Para espécies herbívoras e onívoras, o teor de lisina na ração é de aproximadamente 1,5\%, ou aproximadamente 5\% da proteína da ração (NRC, 1993). RUCHIMAT et al. (1997), em estudo realizado objetivando determinar a exigência de lisina para juvenis de yellowtail (Seriola quinqueradiata) $(68,2$ g), obtiveram os melhores resultados de desempenho com a ração contendo $1,78 \%$ de lisina $(4,13 \%$ da proteína bruta).

Utilizando rações purificadas para juvenis de tilápia do Nilo, SANTIAGO \& LOVELL (1988), estimaram exigência de $1,43 \%$ de lisina. Para esta espécie na fase de terminação, poucos foram os estudos realizados para determinar as exigências de lisina em rações práticas. Essas informações são importantes para permitir a elaboração de rações completas que possibilitem maximizar a retenção do nitrogênio e, conseqüientemente, possibilitar a criação sustentável de peixes, principalmente em sistemas que utilizam elevadas densidades.

A determinação da exigência de lisina permite adequada suplementação de aminoácidos e/ ou combinação de ingredientes para se obter melhor balanceamento de aminoácidos e, consequentemente, o retorno econômico, através do melhor desempenho e qualidade da carcaça dos peixes.

O presente trabalho teve como objetivo determinar a exigência de lisina pela tilápia do Nilo (Oreochromis niloticus) na fase de terminação, através da avaliação do desempenho.

\section{MATERIALEMÉTODOS}

O experimento foi conduzido no Laboratório de Aqüicultura, da Universidade Estadual de Maringá - UEM, Maringá-PR, durante 50 dias, de março a maio de 2001 .

Foram utilizados 72 peixes sexualmente revertidos da linhagem tailandesa, com peso vivo inicial médio de $117,9 \pm 0,67 \mathrm{~g}$, originados da Piscicultura Araucária Belmonte, Rolândia - PR. Os peixes foram distribuídos em 12 tanques com volume de $1000 \mathrm{~L}$ cada, em quatro tratamentos e três repetições, sendo a unidade experimental constituída por um tanque com seis peixes. Em cada tanque, foi mantido um sistema individual de renovação da água (5\%/dia), aeração constante através de pedra porosa acoplada a um soprador central, sendo cobertos com tela sombrite (70\%), para minimizar a produção primária.

Foi utilizada uma ração referência, de forma a atender a relação energia/proteína, recomendada pelo 
NRC (1993) para tilápias, sendo elaborada com proteína do farelo de milho, farelo de soja e glúten de milho. Foram avaliados teores de inclusão de 1,0; 3,0; 5,0 e $7,0 \mathrm{~g} / \mathrm{kg}$ de ração de L-lisina $\mathrm{HCl}(78,5 \%)$, resultando em rações com 1,$13 ; 1,27 ; 1,42$ e $1,57 \%$ de lisina, respectivamente (Tabelas 1 e 2 ).

O preparo e confecção das rações foram realizados de acordo com a metodologia proposta por FURUYA et al. (2000). O arraçoamento foi realizado à vontade até saciedade aparente, parcelado em três vezes às $8,13,18 \mathrm{~h}$.

Ao final do experimento, após jejum de $24 \mathrm{~h}$, todos os peixes foram pesados em balança digital $(0,01 \mathrm{~g})$. Após pesagem final, dois peixes de cada unidade experimental foram utilizados para avaliação do rendimento de carcaça (carcaça inteira e isenta de cabeça, pele, vísceras e nadadeiras ), teor de gordura viceral (gordura visceral $(\mathrm{g}) / \mathrm{peso}$ do peixe $(\mathrm{g}))$ e índice hepato somático. A taxa de eficiência protéica foi calculada de acordo com a

Tabela 1 - Composição percentual da ração referência

\begin{tabular}{|c|c|c|c|c|}
\hline \multirow[b]{2}{*}{ Ingrediente $(\%)$} & \multicolumn{4}{|c|}{ Lisina na ração (\%) } \\
\hline & 1,13 & 1,27 & 1,42 & 1,57 \\
\hline Milho & 48,01 & 47,81 & 47,61 & 47,41 \\
\hline Farelo de soja & 26,00 & 26,00 & 26,00 & 26,00 \\
\hline Glúten de milho & 9,00 & 9,00 & 9,00 & 9,00 \\
\hline Farelo de trigo & 8,00 & 8,00 & 8,00 & 8,00 \\
\hline Farinha de peixe & 4,00 & 4,00 & 4,00 & 4,00 \\
\hline Fosfato bicálcico & 2,40 & 2,40 & 2,40 & 2,40 \\
\hline Óleo de soja & 1,00 & 1,00 & 1,00 & 1,00 \\
\hline L-treonina & 0,10 & 0,10 & 0,10 & 0,10 \\
\hline L-Lisina $\mathrm{HCl}$ & 0,10 & 0,30 & 0,50 & 0,70 \\
\hline DL-metionina & 0,22 & 0,22 & 0,22 & 0,22 \\
\hline Supl. Min. e vit. ${ }^{1}$ & 0,50 & 0,50 & 0,50 & 0,50 \\
\hline Sal comum & 0,50 & 0,50 & 0,50 & 0,50 \\
\hline Vitamina $C^{2}$ & 0,05 & 0,05 & 0,05 & 0,05 \\
\hline $\mathrm{BHT}^{3}$ & 0,02 & 0,02 & 0,02 & 0,02 \\
\hline Alginato $^{4}$ & 0,10 & 0,10 & 0,10 & 0,10 \\
\hline Total & $\begin{array}{c}100,0 \\
0\end{array}$ & 100,00 & 100,00 & 100,00 \\
\hline
\end{tabular}

\footnotetext{
${ }^{1}$ Suplemento mineral e vitamínico (Supremais): composição por $\mathrm{kg}$ do: Vit. $\mathrm{A}=1200.000$ UI; vit. $\mathrm{D} 3=200.000$ UI; vit. $\mathrm{E}=$ $12.000 \mathrm{mg}$; vit. $\mathrm{K} 3=2.400 \mathrm{mg}$; vit. $\mathrm{B} 1=4.800 \mathrm{mg}$; vit. $\mathrm{B} 2=$ $4.800 \mathrm{mg}$; vit. B6 $=4.000 \mathrm{mg}$; vit. $\mathrm{B} 12=4.800 \mathrm{mg}$; ác. fólico= $1.200 \mathrm{mg}$; pantotenato de $\mathrm{Ca}=12.000 \mathrm{mg}$; vit. $\mathrm{C}=48.000 \mathrm{mg}$; biotina $=48 \mathrm{mg} ;$ colina $=65.000 \mathrm{mg}$; ácido nicotínico $=24.000$ $\mathrm{mg} ; \mathrm{Fe}=10.000 \mathrm{mg} ; \mathrm{Cu}=600 \mathrm{mg} ; \mathrm{Mn}=4.000 \mathrm{mg} ; \mathrm{Zn}=6.000$ $\mathrm{mg} ; \mathrm{I}=20 \mathrm{mg} ; \mathrm{Co}=2 \mathrm{mg}$ e $\mathrm{Se}=20 \mathrm{mg}$;

${ }^{2}$ Vitamina C: sal cálcica 2-monofosfato de ácido ascórbico com (42\% de princípio ativo)

${ }^{3}$ Butil Hidróxi Tolueno.

${ }^{4}$ Aglutinante
}

Tabela 2 - Composição química das rações (base na matéria natural)

\begin{tabular}{|c|c|c|c|c|}
\hline \multirow[b]{2}{*}{ Ingrediente (\%) } & \multicolumn{4}{|c|}{ Lisina na ração (\%) } \\
\hline & 1,13 & 1,27 & 1,42 & 1,57 \\
\hline Matéria seca $(\%)^{1}$ & 88,48 & 88,50 & 88,50 & 88,50 \\
\hline $\begin{array}{l}\text { Energia digestível } \\
(\mathrm{kcal} / \mathrm{kg})^{2}\end{array}$ & 3094,92 & 3091,57 & 3091,12 & 3090,66 \\
\hline Proteína bruta $(\%)^{1}$ & 25,00 & 25,10 & 25,12 & 25,13 \\
\hline Extrato etéreo $(\%)^{1}$ & 2,49 & 2,49 & 2,49 & 2,49 \\
\hline Fibra bruta $(\%)^{1}$ & 3,20 & 3,20 & 3,20 & 3,20 \\
\hline $\begin{array}{l}\text { Fósforo disponível } \\
(\%)^{2}\end{array}$ & 0,60 & 0,60 & 0,60 & 0,60 \\
\hline Cálcio $(\%)^{1}$ & 0,87 & 0,87 & 0,87 & 0,87 \\
\hline $\begin{array}{l}\text { Metionina + cistina } \\
(\%)^{1}\end{array}$ & 1,07 & 1,07 & 1,07 & 1,07 \\
\hline Lisina $(\%)^{1}$ & 1,13 & 1,27 & 1,42 & 1,57 \\
\hline Arginina $(\%)^{1}$ & 1,47 & 1,47 & 1,47 & 1,47 \\
\hline Triptofano $(\%)^{1}$ & 0,26 & 0,26 & 0,26 & 0,26 \\
\hline Treonina $(\%)^{1}$ & 1,05 & 1,05 & 1,05 & 1,05 \\
\hline Custo $(\mathrm{R} \$ / \mathrm{kg})$ & 0,431 & 0,439 & 0,440 & 0,441 \\
\hline Total & 100,00 & 100,00 & 100,00 & 100,00 \\
\hline
\end{tabular}

${ }^{1}$ Calculada de acordo com Rostagno (2000)

${ }^{2}$ Calculada de acordo com Furuya et al. (2000), Miranda et al. (2000) e Pezzato et al. (2002)

expressão descrita por JAUNCEY \& ROSS (1982). A avaliação do custo médio em ração por quilograma de peso vivo ganho foi realizada de acordo com expressão descrita por BELLAVER et al. (1985).

$$
\begin{aligned}
& \text { Em que: } T E P=\frac{G P}{P C} \\
& \mathrm{GP}=\text { ganho de peso }(\mathrm{g}) ; \\
& \mathrm{PC}=\text { proteína consumida }(\mathrm{g}) .
\end{aligned}
$$

Diariamente, foram tomadas as medidas de temperatura ( 8 e 18 h) da água dos tanques. A cada quinze dias, foram realizadas as medidas de $\mathrm{pH}$, oxigênio dissolvido $(\mathrm{mg} / \mathrm{L})$ e condutividade elétrica $(\mathrm{mSm} / \mathrm{cm})$ da água de cada tanque. Estes dados foram obtidos através de Kit digital portátil.

Os dados foram submetidos às análises de variância e regressão polinomial através do programa estatístico SAEG - Sistema de Análises Estatísticas e Genéticas descrito por EUCLYDES (1983).

\section{RESULTADOS E DISCUSSÃO}

Foram obtidos valores médios de $22,3 \pm 1,55$ ${ }^{\circ} \mathrm{C} ; 5,24 \pm 0,894 \mathrm{mg} / \mathrm{L} ; 7,06 \pm 0,117 \mathrm{e} 292,08 \pm 13,8 \mathrm{mSm} / \mathrm{cm}$, para temperatura, oxigênio dissolvido, $\mathrm{pHe}$ condutividade elétrica da água dos tanques, respectivamente. A 
temperatura média obtida foi inferior a recomendada por POPMA \& GREEN (1990), para máximo crescimento, de 29 a $31^{\circ} \mathrm{C}$, devido 'a época do ano em que o experimento foi conduzido (março a maio), enquanto os valores de oxigênio dissolvido e de $\mathrm{pH}$ encontram-se dentro da faixa recomendada por estes autores, para as tilápias.

A relação proteína:energia das dietas experimentais (Tabela 1) de 84,10 (mg de proteína/kcal). $\mathrm{Na}$ tabela 3, encontram-se os valores médios de desempenho da tilápia do Nilo em função do teor de inclusão de lisina na ração. Não foi observado efeito $(\mathrm{P}>0,05)$ dos teores de inclusão deste aminoácido sobre a conversão alimentar, porcentagem de gordura visceral e índice hepato-somático. Os resultados de índice hepato-somático e gordura visceral concordam com os de BAI \& GATLIN (1994), em estudo realizado com bagre do canal (91g).

Com o aumento nos teores de inclusão de lisina na ração, foi observado efeito quadrático $(\mathrm{P}<0,05)$, sobre o ganho de peso, estimando-se o valor de $1,42 \%$ de lisina, correspondente a 5,7\% da proteína bruta ou 4,8 $\mathrm{mg}$ de lisina/kcal de energia digestível da ração, para obter maior valor dessa variável (Figura 1).

Este valor $(1,42 \%)$ aproxima-se ao encontrado por SANTIAGO \& LOVELL (1988), que estimaram $1,43 \%$ de lisina $(5,1 \%$ da proteína ou 4,8mg de lisina/ kcal de energia digestível na ração), para tilápia do Nilo, na fase inicial, sendo inferior ao obtido por MURTHY \& VARGHESE (1997), de 2,24\% em trabalho realizado com juvenis de carpa, ainda que a proporção de lisina em relação à proteína estimada por esses últimos autores, de 5,6\% de lisina em relação à proteína, esteja próxima à encontrada no presente estudo.
O valor de lisina determinado para proporcionar maior ganho de peso foi inferior ao obtido por RUCHIMAT et al. (1997), que estimaram exigência de $1,78 \%$ de lisina $(4,13 \%$ da proteína) para juvenis $(68,2 \mathrm{~g})$ de "yellowtail" e ao determinado por FAGBENRO et al. (1998) para juvenis de bagre africano, que foi de $2,29 \%$ de lisina da dieta e 5,73\% da proteína bruta.

Para peixes carnívoros, os estudos realizados mostram diferenças no teor de inclusão e na proporção de lisina em relação à proteína. TIBALDI \& LANARI (1991) determinaram exigência de 2,17\% de lisina $(4,34 \%$ da proteína) para "sea bass" $(0,85 \mathrm{~g})$ enquanto KEEMBIYEHETTY \& GATLIN (1992) estimaram exigência de $1,41 \%$ de lisina $(4,03 \%$ da proteína), para juvenis de "striped bass" (8g).

Para juvenis de "flounder" japonês ( $1 \mathrm{~g})$, FORSTER \& OGATA (1998) estimaram valor de 1,55\% de lisina (3,3\% da proteína) para maior ganho de peso. Neste mesmo trabalho, avaliando ganho de peso determinaram exigência de $1,73 \%$ de lisina $(3,6 \%$ da proteína) para o "red sea bream" (1g).

Trabalhando com truta arco-íris com aproximadamente 12,4 g de peso vivo, KIM et al. (1992) determinaram exigência de $1,30 \%$ de lisina na ração (3,71\% da proteína). Valores próximos foram obtidos por BERGE et al. (1998), para o salmão do Atlântico (Salmo salar), que estimaram o valor de 1,80\% de lisina na ração para máximo ganho de peso $(3,6 \%$ de lisina em relação à proteína bruta).

Para a taxa de eficiência protéica, foi observado efeito quadrático $(\mathrm{P}<0,05)$ dos teores de inclusão de lisina, sendo que o maior valor foi estimado com $1,35 \%$ de lisina (5,4\% da proteína)

Tabela 3- Valores médios de desempenho da tilápia do Nilo, alimentada com rações contendo teores crescentes de lisina

\begin{tabular}{|c|c|c|c|c|c|}
\hline \multirow[b]{2}{*}{ Variável } & \multicolumn{5}{|c|}{ Lisina na ração $(\%)$} \\
\hline & 1,13 & 1,27 & 1,42 & 1,57 & $\mathrm{CV}(\%)^{1}$ \\
\hline Peso inicial (g) & 118,63 & 116,92 & 118,4 & 117,65 & 2,22 \\
\hline Peso final $(\mathrm{g})$ & 187,9 & 190,73 & 208,60 & 196,46 & 4,05 \\
\hline Ganho de peso $(\mathrm{g})^{2}$ & 69,27 & 73,81 & 90,20 & 78,82 & 9,05 \\
\hline Conversão alimentar & 1,32 & 1,34 & 1,25 & 1,33 & 7,77 \\
\hline Taxa de eficiência protéica ${ }^{2}$ & 3,03 & 3,09 & 3,20 & 3,00 & 5,87 \\
\hline Índice hepato-somático (\%) & 1,88 & 1,91 & 1,93 & 1,61 & 31,15 \\
\hline Gordura visceral (\%) & 0,59 & 0,76 & 0,64 & 0,74 & 11,87 \\
\hline Sobrevivência (\%) & 100,00 & 100,00 & 100,00 & 100,00 & 0,00 \\
\hline Carcaça $(\%)$ & 44,70 & 46,47 & 46,34 & 46,36 & 1,59 \\
\hline $\mathrm{R} \$ / \mathrm{kg}$ de ganho de peso & 0,569 & 0,588 & 0,550 & 0,587 & 2,69 \\
\hline
\end{tabular}

${ }^{1} \mathrm{CV}=$ coeficiente de variação

${ }^{2}$ Efeito quadrático $(\mathrm{P}<0,05)$ : ganho de peso $\left(\mathrm{Y}=-335,0320+589,9030 \mathrm{X}-207,1190 \mathrm{X}^{2}\right.$;

$\left.\mathrm{R}^{2}=0,66\right)$ e taxa de eficiência protéica $\left(\mathrm{Y}=-2,4752+8,3413 \mathrm{X}-3,0849 \mathrm{X}^{2} ; \mathrm{R}^{2}=0,80\right)$ 


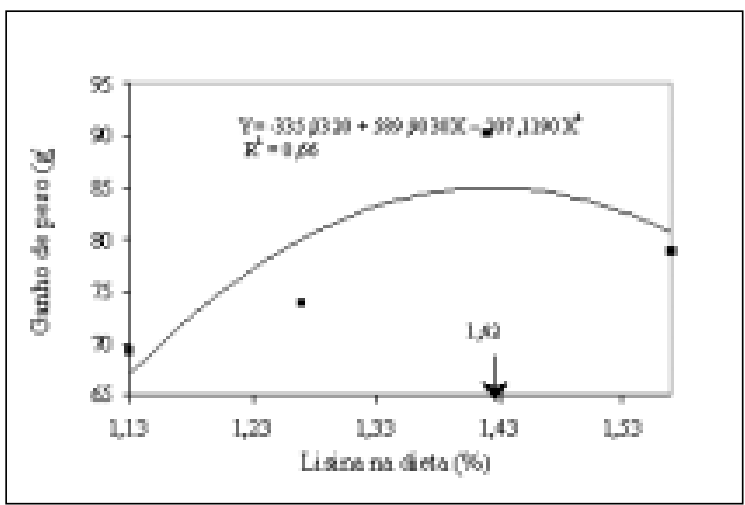

Figura 1 - Ganho de peso da tilápia do Nilo, alimentada com rações contendo teores crescentes de lisina.

(Figura 2). Valor superior foi obtido por RUCHIMAT et al. (1997), de 1,85\% de lisina (4,29\% da proteína), para melhor retenção de nitrogênio na carcaça de "yellowtail". Estes resultados foram semelhantes aos encontrados por BERGE et al. (1998), para o salmão do Atlântico, de 1,6\% de lisina na ração para melhor taxa de eficiência protéica (3,2\% de lisina em relação à proteína bruta). TIBALDI \& LANARI (1991), em estudo realizado com peixes carnívoros, determinaram exigência de $2,17 \%$ de lisina (4,34\% da proteína bruta) para "sea bass" $(0,85 \mathrm{~g})$, para máxima taxa de eficiência protéica. Valores próximos foram encontrados por FORSTER \& OGATA (1998), para juvenis de "flounder" japonês $(1 \mathrm{~g})$, que estimaram valores de $2,16 \%$ de lisina (4,6\% da proteína bruta) e, para o "red sea bream" (1g). Estes mesmos autores determinaram exigência de $2,11 \%$ de lisina $(4,4 \%$ da proteína bruta) para melhor taxa de eficiência protéica.

As diferenças nos resultados podem também estar relacionadas com a espécie (linhagem) e os peixes estudados, composição da ração, manejo alimentar e parâmetros físicos e químicos da água. Os peixes herbívoros e onívoros utilizam mais eficientemente os carboidratos como fonte de energia, o que não ocorre com os carnívoros, que utilizam a proteína como principal fonte para obtenção de energia. Outro fator que influencia a exigência em aminoácidos é o tamanho e a idade dos peixes. Peixes mais jovens apresentam maior exigência em proteína (aminoácidos) quando comparados com peixes mais velhos, devido às diferenças na taxa de retenção e deposição de proteína (COWEY, 1994). Além disso, valor nutricional (digestibilidade) da lisina varia entre ingredientes de acordo com a sua composição em aminoácidos e processamento utilizado para sua obtenção.

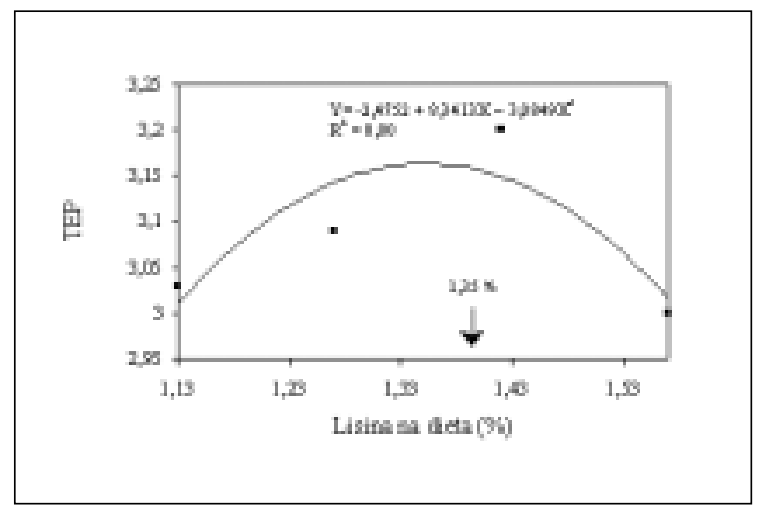

Figura 2 - Taxa de eficiência protéica (TEP) da tilápia do Nilo, alimentada com rações contendo teores crescentes de lisina.

Comparando a taxa de lixiviação dos aminoácidos sintéticos determinada por ZARATE \& LOVELL (1997), que foi de aproximadamente $13 \%$ após 15 segundos de imersão na água, com a de $2 \%$ para os aminoácidos ligados à proteína dos ingredientes, deduz-se que o aumento na freqüência de arraçoamento reduz o tempo de exposição do grânulo para ocorrer lixiviação deste aminoácido. Além disso, provavelmente proporciona um "pool" mais estável de aminoácidos plasmáticos, ocorrendo liberação do mesmo a uma taxa compatível com a capacidade de utilização, maximizando a retenção de nitrogênio.

Os maiores valores de rendimento de carcaça foram obtidos com as rações contendo teores igual ou acima de 1,27\% de lisina, destacando-se a maior porcentagem de carcaça $( \pm 2 \%)$ limpa obtida nos peixes alimentados com essas rações, em relação à ração com $1,13 \%$ de lisina.

Pela análise econômica, o menor custo para se obter um quilograma de ganho de peso foi obtido com a ração contendo $1,42 \%$ de lisina na dieta. Ainda que o ganho de peso dos peixes alimentados com a ração contendo $1,27 \%$ de lisina tenha sido superior $(6,55 \%)$ ao obtido com o dos peixes que receberam a ração com $1,13 \%$ de lisina, o custo por quilograma de ganho de peso obtido com esta última ração foi inferior, devido ao menor nível de inclusão deste aminoácido na ração.

A determinação da exigência de lisina pela tilápia do Nilo é importante para permitir a elaboração de rações com adequado balanceamento de aminoácidos, possibilitando a aplicação do conceito de proteína ideal, para diminuir a quantidade de proteína da ração, diminuindo assim a excreção de nitrogênio para a água. 


\section{CONCLUSÕES}

Os dados obtidos no presente estudo mostram que a tilápia do Nilo, na fase de terminação, apresenta exigência de $1,42 \%$ (5,7\% da proteína ou $4,8 \mathrm{mg}$ de lisina/kcal de energia digestível na ração) de lisina, para melhor desempenho.

\section{REFERÊNCIASBIBLIOGRÁFICAS}

BAI, S.C.; GATLIN, D.M. Effects of L-lysine supplementation of diets with different protein levels and sources on channel catfish, Ictalurus punctatus (Rafinesque). Aquaculture and Fisheries Management, v.25, p.465-474, 1994.

BELLAVER, C. et al. Radícula de malte na alimentação de suínos em crescimento e terminação. Pesquisa Agropecuária Brasileira, v.20, n.8, p.969-974, 1985.

BERGE G.E.; SVEIER, H.; LIED, E. Nutrition of Atlantic salmon (Salmo salar); the requirement and metabolic effect of lysine. Comparative Biochemistry and Physiology, v.120(A), p.477-485, 1998.

CHEN, H.Y.; LEU, Y.T.; ROELANTS, I. Effective supplementation of arginine in diets of juvenile marine shrimp, Penaeus monodon. Aquaculture, v.108, p.87-95, 1992.

COWEY, C.B. Amino acid requirements of fish: a critical appraisal of present values. Aquaculture, v.124, p.1-11, 1994.

DAVIES, S.J.; MORRIS, P.C.; BAKER, R.T. Partial substitution of fish meal and full-fat soya bean meal with wheat gluten and influence of lysine supplementation in diets for rainbow trout, Oncorhynchus mykiss (Walbaum). Aquaculture Research, v.28, p.317-328, 1997.

DEGANI, G.; REVACH, A. Digestive capabilities of three commensal fish species: carp, Cyprinus carpio L., tilapia, Oreochromis aureus x $\boldsymbol{O}$. niloticus, and African catfish, Clarias gariepinus (Burchell, 1882). Aquaculture and Fisheries Management, v.22, p.397-403, 1991.

ENGLISH, W.R.; SCHWEDLER, T.E.; DYCK, L.A. Aphanizomenon flos-aquae, a toxic blue green alga in commercial channel catfish, Ictalurus punctatus, ponds: a case history. Journal of Applied Aquaculture, v.3, p.195-209, 1993.

EUCLYDES, R.F. Manual de utilização do programa SAEG (Sistema para Análises Estatísticas e Genéticas). Viçosa : UFV, 1983. 59p.

FAGBENRO, O.A. et al. Dietary lysine requirement of the African catfish, Clarias gariepinus. Journal of Applied Aquaculture, v.8, p.71-77, 1998.

FORSTER, I.; OGATA, H.Y. Lysine requirement of juvenile japanese flounder (Paralichthys olivaceus) and juvenile red sea bream (Pagrus major). Aquaculture, v.161, p.131-142, 1998.

FURUYA, W.M. et al. Exigência de metionina + cistina pela tilápia do Nilo (Oreochromis niloticus), na fase inicial. In: REUNIÃO DA SOCIEDADE BRASILEIRA DE ZOOTECNIA, 38., 2001, Piracicaba. Anais... Piracicaba : SBZ, 2001. p.14181419 .
FURUYA, W.M.; HAYASHI, C.; FURUYA. V.R.B. Exigência de proteína para alevino revertido de tilápia do Nilo (Oreochromis niloticus). Revista da Sociedade Brasileira de Zootecnia, v.29, n.6, p.1912-1917, 2000.

HANLEY, F. The digestibility of foodstuffs in the effects of feeding selectivity on digestibility determination in tilapia, Oreochromis niloticus (L.). Aquaculture, v.66, p.163-179, 1987.

HILDSORF, A.W.S. Genética e cultivo de tilápias vermelhas, uma revisão. Boletim do Instituto de Pesca, v.22, p.73-87, 1995.

JAUNCEY, K.; ROSS, B. A guide to tilapia feed and feeding. cotland : University of Stirling, 1982. $111 \mathrm{p}$.

KEEMBIYEHETTY, C.N.; GATLIN, D.M. Dietary lysine requirement of juvenile hybrid striped bass (Morone chrysops x M. saxatilis). Aquaculture, v.104, n.3/4, p.271-277, 1992.

KIM, K.; KAYES, T.B.; AMUNDSON, C.H. Requirements for lysine and arginine by rainbow trout (Oncorhynchus mykiss). Aquaculture, v.106, p.333-344, 1992.

LIM, C. Effect of dietary $\mathrm{pH}$ on amino acid utilization by shrimp (Penaeus vannamei). Aquaculture, v.114, p.293303, 1993.

MIRANDA, E.C. et al. Relação cálcio/fósforo disponível em rações para a tilápia do Nilo (Oreochromis niloticus). Revista da Sociedade Brasileira de Zootecnia, v.29, n.6, p.21622171, 2000 .

MURTHY, H.S.; VARGHESE, T.J. Dietary requirement of juveniles of the indian major carp, Labeo rohita, for the essential amino acid lysine. The Israeli Journal of Aquaculture - Bamidgeh, v.49, n.1, p.19-24, 1997 .

NATIONAL RESEARCH COUNCIL - NRC. Nutrient Requirements of warmwater fishes and shellfishes. Washington : National Academy, 1993. 102p.

PEZZATO, L.E. et al. Digestibilidade aparente de ingredientes pela tilápia do Nilo (Oreochromis niloticus). Revista da Sociedade Brasileira de Zootecnia, Viçosa. (no prelo), 2002.

POPMA, T.J.; GREEN, B.W. Sex reversal of tilapia in earthen ponds. Aquaculture production manual. Alabama : Auburn Unyversity, Alabama Research and Development, 1990. 15p. (Series 35).

RICHIE, M.; BROWN, P.B. Availability of phosphorus from feedstuffs fed to rainbow trout, Oncorhynchus mykiss. Aquaculture, v.142, p.269-282, 1996.

ROSTAGNO, H.S. Tabelas brasileiras para aves e suínos: composição de alimentos e exigências nutricionais. Viçosa : UFV, 2000. 141p.

RUCHIMAT, T. et al. Quantitative lysine requirement of yellowtail (Seriola quinqueradiata). Aquaculture, v.158, p.331-339, 1997.

SANTIAGO, C.B.; LOVELL, R.T. Amino acid requirements for growth of Nile tilapia. Journal of Nutrition, v.118, p.1540-1546, 1988 . 
SCHUHMACHER, A.; WAX, C.; GROPP, J.M. Plasma amino acids in rainbow trout (Oncorhynchus mykiss) fed intact protein or a crystalline amino acid diet. Aquaculture, v.151, p.15-28, 1997.

TANTIKITTI, C.; MARCH, B.E. Dynamics of plasma free amino acids in rainbow trout (Oncorhynchus mykiss) under variety of dietary conditions. Fish Physiol Biochem, v.14, p.179-194, 1995.

TIBALDI, E.; LANARI, D. Optimal dietary lysine levels for growth and protein utilisation fingerling sea bass (Dicentrarchus labrax L.) fed semipurified diets. Aquaculture, v.95, n.3/4, p.297-304, 1991

VAN DER PLOEG, M.; BOYD, C.E. Geosmin production by cyanobacteria (blue green algae) in fish ponds at Auburn,
Alabama. Journal of the World Aquaculture Society, v.22, p.207-216, 1991 .

VAN DER PLOEG, M.; TUCKER, C.S. Seasonal trends in flavor quality of channel catfish, Ictalurus punctatus, from commercial ponds in Mississippi. Journal of Applied Aquaculture, v.3, p.121-140, 1994.

YAMADA, S. Plasma amino acid changes in rainbow trout force-fed casein and corresponding amino acid mixture. Bull Jpn.Soc Sci Fish, v.47, p.1035-1040, 1981.

ZARATE, D.D.; LOVELL, R.T. Free lysine (L-lysine.HCl) is utilized for growth less efficiently than protein-bound lysine (soybean meal) in practical diets by young channel catfish (Ictalurus punctatus). Aquaculture, v.159, p.87100, 1997. 